PAIVA, W.O.; LIMA, J.A.A.; PINHEIRO NETO, L.G; RAMOS, N.F.; VIEIRA, F.C. Melão Tupã: produtividade, qualidade do fruto e resistência a viroses. Horticultura Brasileira, Brasília, v 21, n. 3, p. 539-544, julho-setembro 2003.

\title{
Melão Tupã: produtividade, qualidade do fruto e resistência a viroses
}

\author{
Waldelice Oliveira de Paiva ${ }^{1}$; José Albérsio de Araújo Lima ${ }^{2}$; Luis G. Pinheiro Neto ${ }^{1}$; Najara Frota \\ Ramos $^{2}$;Flávia Campos Vieira ${ }^{1}$ \\ ${ }^{1 / E m b r a p a ~ A g r o i n d u ́ s t r i a ~ T r o p i c a l, ~ C . ~ P o s t a l ~ 3761, ~ 60511-110 ~ F o r t a l e z a-C E ; ~ E-m a i l ~ w a l d e @ c n p a t . e m b r a p a . b r ; ~}{ }^{2}$ UFC, C. Postal 6046, \\ Fortaleza-CE; E-mail albersio@ufc.gov.br
}

\section{RESUMO}

Progênies de melão (Cucumis melo L.) cv. Tupã, um tipo que associa as características favoráveis do fruto do melão Amarelo e do melão Cantaloupe, foram submetidas à inoculação artificial com cinco vírus [Watermerlon mosaic virus (WMV-2), Papaya ringspot virus (PRSV-w), Zucchini yelow mosaic virus (ZYMV), Squash mosaic virus (SqMV) e Cucumber mosaic virus (CMV)], em casa de vegetação. A produção e a qualidade do fruto foram avaliadas em campo. Progênies de três famílias mostraram resistência ao PRSV-w e ao ZYMV, algumas manifestaram resistência também ao WMV-2. Cerca de $63,15 \%$ apresentaram resistência somente ao PRSV-w e 52,63\% somente ao ZYMV. A resistência para a combinação do PRSV-w e ZYMV ocorreu em $42,10 \%$ das progênies e a resistência tripla a PRSV-w, ZYMV e WMV-2 em 36,84\%. Uma progênie foi resistente aos quatro vírus (PRSV-w, ZYMV, WMV-2 e CMV). Para o caráter concentração de colheita o comportamento das progênies foi muito variável, observando-se progênies onde a metade dos frutos foram colhidos até os 80 dias, e outras onde até os 70 dias nenhum fruto havia sido colhido. Em relação ao tipo Amarelo, foram muito tardias para a maturação dos frutos, mas mostraram semelhanças com o fruto para peso médio, formato, diâmetro interno e espessura da polpa. A firmeza da polpa variou de $7,78 \mathrm{~N}$ a $35,6 \mathrm{~N}$, sendo que em $20 \%$ das progênies a firmeza da polpa foi superior a $20 \mathrm{~N}$, muito semelhante aos melões do tipo Cantaloupe.

Palavras-chave: Cucumis melo L., resistência, vírus, produção, qualidade do fruto.

\begin{abstract}
Tupã melon: agronomic performance, fruit quality and virus resistance

Progenies of melon (Cucumis melo L.) cv. Tupã, that associate the favorable fruit characteristics of yellow casaba cantaloupe types, were submitted to artificial inoculation with five virus: Watermerlon mosaic virus (WMV-2), Papaya ringspot virus (PRSV-W), Zucchini yellow mosaic virus (ZYMV), Squash mosaic virus (SqMV) and Cucumber mosaic virus (CMV), in greenhouse. Yield and the fruit quality were evaluated in the field. Progenies of three families showed marked resistance to PRSV-W and to ZYMV, also some manifested resistance to WMV-2. More than 50\% showed isolated resistance to PRSV-W (63,15\%) and to ZYMV (52,63\%). The resistance to both PRSV-W and ZYMV occurred in $42,10 \%$ of the progenies and the triple resistance to PRSV-W, ZYMV and to WMV-2 was detected in $36,84 \%$. One progeny was resistant to four viruses (PRSV-W, ZYMV, WMV-2 and CMV). The progenies were very variable on harvesting date, some being very dispersed for harvest, others with no fruits harvested before 80 days, and others presenting a highly concentrated harvest period. In comparison to the yellow casaba melon, the progenies were very late in fruit maturation, but similar for fruit weight, fruit shape, flesh thickness and internal diameter cavity. Flesh firmness varied from $7,78 \mathrm{~N}$ to $35,6 \mathrm{~N}$, and $20 \%$ of these progenies presented the firmness superior to $20 \mathrm{~N}$, very similar to cantaloupe melon type.
\end{abstract}

Keywords: Cucumis melo L., virus resistance, yield, fruit quality.

\section{(Recebido para publicação em 12 de julho de 2002 e aceito em 30 de abril de 2003)}

$\mathrm{O}$ conceito de qualidade em frutas e hortaliças varia para produtores, distribuidores e consumidores. No caso específico do melão, para o produtor, a qualidade refere-se à precocidade, robustez (resistência às doenças) e produtividade, enquanto que o distribuidor entende por qualidade a resistência do fruto ao manuseio e à longa vida de prateleira. Por outro lado, o consumidor considera a qualidade primeiramente pela aparência ou apresentação externa (formato, textura cor da casca), quando escolhe o fruto e, mais tarde, pela aparência interna (cor, textura e sabor da polpa), quando vai consumir o produto. Dessa forma, uma cultivar de melão para ter plena aceitação precisa aliar as características de produção, as caracterís- ticas inerentes à polpa (coloração, espessura da polpa, teores de açúcares e sabor) com aquelas que conferem maior conservação do fruto (McCreight et al.1993).

Os produtores enfatizam que, para ter lucratividade, o melão precisa superar a faixa de 25 toneladas/ha. Alguns híbridos superam 40 toneladas. Entretanto, existem dificuldades na indicação de um mesmo híbrido para cultivo em toda essa região, dada a alta interação dos genótipos com o ambiente (Gurgel, 2000). Por outro lado, essa produtividade é comprometida caso ocorram viroses, cujo controle químico é pouco eficiente. De acordo com RubiesAntonell et al. (1996), o vírus do zucchini amarelo se disseminou com muita rapidez na Itália e em dois anos já era responsável por $30 \%$ das infecções no melão.

Embora as plantas não sejam destruídas pelos vírus, os cultivos infectados têm o processo de produção severamente interrompido, produzindo frutos anormais e/ou deixando de produzir (Clough 1995). De acordo com Lima et al. (1996) sete vírus já foram constatados em cucurbitáceas no Brasil, entre eles o vírus-2 do mosaico da melancia (WMV-2), o vírus da mancha anelar do mamoeiro (PRSV-w), vírus do mosaico amarelo do zucchini (ZYMV), o vírus do mosaico do pepino (CMV) e o vírus do mosaico da abóbora (SqMV). O cultivo de genótipos resistentes tem sido indicado como a melhor forma de con- 
trole, o que deve ser considerado durante o processo seletivo do meloeiro.

$\mathrm{O}$ melão preferido pelos produtores no Nordeste é do tipo Amarelo, dado o longo período de conservação pós-colheita, podendo ser oferecido em mercados distantes sem uso de cadeia de frio. Este melão, entretanto, passa por uma fase de queda de consumo, tanto no mercado internacional quanto no local. Os motivos alegados são o sabor fraco (baixo teor de sólidos solúveis) e a dificuldade de constatar se o fruto está completamente maduro. Por este motivo, no mercado interno, os supermercadistas passaram a aumentar a oferta de melão Cantaloupe, o qual permite identificar o ponto de consumo pelo aroma. Entretanto, por ser mais perecível que o melão amarelo, não tem conservação suficiente para permitir o transporte marítimo, reduzindo assim as possibilidades de exportação para o hemisfério norte.

Para aliar os atributos de produção e de qualidade de fruto em um único genótipo que atenda ao mercado, foi desenvolvido o melão Tupã, um tipo que associa características do melão Amarelo e do Cantaloupe (Paiva et al., 2000b; 2001), com frutos com a casca amarelo ouro, enrugada e polpa salmão. Neste tipo ocorrem variações no formato do fruto, coloração da casca e da polpa (Paiva et al. 2000b). Esse germoplasma está sendo objeto de melhoramento e o presente trabalho avalia progênies para as características relacionadas à resistência as doenças viróticas, produção e a qualidade do fruto.

\section{MATERIAL E MÉTODOS}

O comportamento de 24 progênies de melão Tupã aos principais vírus que infectam as cucurbitáceas no Nordeste brasileiro (PRSV-w, WMV-2, ZYMV, CMV e SqMV) foi avaliado em casa de vegetação. As progênies $S_{1}$ de melão Tupã (Paiva et al., 2000b), obtidas pela autofecundação de cinco plantas selecionadas dentro do tipo Tupã. Cada planta foi considerada uma família, e as descendentes, originaram as progênies $S_{1}$.

Sementes de cada progênie foram semeadas em vasos em solo esterilizado, constituído por uma parte de ester- co e duas de terra. Após o desbaste, deixou-se quatro plantas por vaso. Quatro plantas de cada progênie foram inoculadas artificialmente com cada vírus, e quatro plantas serviram de testemunhas.

A primeira inoculação foi realizada 10 dias após a germinação, usando-se como inóculo extrato de plantas sistematicamente infetadas pelos respectivos potyvírus. Uma segunda inoculação foi efetuada somente nas plantas que não apresentaram sintomas decorridos 10 dias após a primeira inoculação. Todas as plantas foram mantidas em casa de vegetação por aproximadamente 30 dias para a observação de reações sintomatológicas e realização de testes sorológicos contra anti-soros para os respectivos vírus.

Para avaliação das características relacionadas à produção foram cultivadas 29 progênies $\mathrm{S}_{1}$ no Campus Experimental de Pacajus, da EmbrapaAgroindústria Tropical, de 05/01 a 06/ 04/01. O experimento foi instalado sob delineamento de blocos ao acaso, com quatro repetições e cinco plantas por parcela. A irrigação e o manejo do experimento seguiram as práticas locais recomendadas para o cultivo comercial.

As progênies foram avaliadas quanto a concentração da colheita (CC), referente à porcentagem de frutos colhidos do total de frutos produzidos aos 80 dias após a semeadura. Para dados de maturidade (MATUR), avaliou-se o número de dias da abertura e polinização da flor feminina até a completa maturação do fruto. Para obtenção da produtividade (PRODU), obteve-se o peso total de frutos na parcela, estimando a produção por hectare.

Para obter as características relacionadas à qualidade dos frutos, os mesmos foram pesados e medidos no diâmetro longitudinal (COMP), diâmetro transversal externo (DE), e diâmetro transversal interno (DI). Com esses valores foram calculados o índice de formato (IF) pela relação COMP/DE, e a espessura da polpa (EP), pela fórmula DE-DI/2. A firmeza do fruto foi medida em amostras dos frutos partidos longitudinalmente e em cada parte medida a resistência com um penetrômetro com pluger de ponta cônica de $8 \mathrm{~mm}$ de diâmetro, na região mediana comestível, eqüidistantes em relação ao comprimento e à espessura da polpa. Os resultados da leitura no aparelho foram convertidos em Newton (N) onde cada 1 Newton corresponde a 1 libra X 4,45.

As análises estatísticas foram realizadas utilizando-se o Programa Genes (Cruz, 1997) sendo que os dados, em porcentagem, sofreram transformação para $\log \mathrm{X}$, antes da análise estatística.

\section{RESULTADOS E DISCUSSÃO}

Com base nas reações sintomatológicas e nos resultados sorológicos (Tabela 1), verificou-se que os vírus em estudo, quando inoculados isoladamente causam danos desde mosaico leve a mosaico severo, com deformações foliares, sendo as progênies classificadas em resistentes e suscetíveis aos cinco vírus estudados. As famílias 1,2 e 5 apresentam progênies que manifestam resistência, principalmente ao PRSV-w e ZYMV, sendo que algumas manifestam também resistência ao WMV-2.

Quando a reação é avaliada isoladamente ou em combinação, a distribuição dos genótipos, de acordo com seu comportamento aos cinco vírus, mostra que doze progênies $(63,15 \%)$ apresentaram resistência isolada ao PRSV-w, e $\operatorname{dez}(52,63 \%)$ ao ZYMV. Para estes dois vírus as progênies apresentaram os maiores índices de resistência, seguido pelo CMV, com 36,84\% das progênies manifestando resistência. A ocorrência de resistência dupla é verificada principalmente para a combinação de PRSV-w e ZYMV, quando oito progênies (42,10\%) mostraram resistência. Enquanto que, a resistência tripla ocorre com maior freqüência $(36,84 \%)$ para PRSV-w, ZYMV e WMV-2 e apenas uma progênie (progênie 22), manifesta resistência a quatro viroses, PRSV-w, ZYMV, WMV-2 e CMV. Os resultados corroboram com os obtidos por Oliveira (2000), quando avaliou 69 híbridos de melão e encontrou oito com resistência a três potyvirus (WMV-2, ZYMV e PRSV). É importante ressaltar que esses híbridos são provenientes de linhagens, obtidas no mesmo material base de onde foi obtido o tipo Tupã; produto da recombinação de diferentes genótipos, muitos dos quais, 
Tabela 1. Comportamento de melão Tupã ao Cucumber mosaic virus (CMV), Papaya ringspot virus, tipo watermelon (PRSV-w), Watermelon mosaic virus-2 (WMV-2), Zucchini yelow mosaic virus (ZYMV) e Squash mosaic virus (SqMV), em casa de vegetação. Fortaleza, UFC, 2001.

\begin{tabular}{|c|c|c|c|c|c|c|c|c|c|}
\hline \multirow{2}{*}{ Progênie } & \multicolumn{2}{|c|}{ CMV } & \multicolumn{2}{|c|}{ PRSV-w } & \multicolumn{2}{|c|}{ WMV-2 } & \multicolumn{2}{|c|}{ ZYMV } & SqMV \\
\hline & Elisa & Sintoma & Elisa & Sintoma & Elisa & Sintoma & Elisa & Sintoma & Elisa Sintoma \\
\hline
\end{tabular}

\section{Família 1}

\begin{tabular}{lllllllllll}
11 & + & $\mathrm{ML}$ & - & $\mathrm{SS}$ & - & $\mathrm{SS}$ & + & $\mathrm{B}, \mathrm{DF}, \mathrm{M}$ & + & $\mathrm{SS}$ \\
12 & + & $\mathrm{ML}$ & - & $\mathrm{SS}$ & + & $\mathrm{SS}$ & - & $\mathrm{SS}$ & + & $\mathrm{M}$ \\
14 & + & $\mathrm{M}$ & - & $\mathrm{SS}$ & - & $\mathrm{SS}$ & - & $\mathrm{SS}$ & + & $\mathrm{M}$ \\
16 & + & $\mathrm{SS}$ & - & $\mathrm{SS}$ & - & $\mathrm{SS}$ & - & $\mathrm{SS}$ & + & $\mathrm{M}$ \\
\hline
\end{tabular}

\begin{tabular}{lllllllllll}
\hline Familia 2 & & & & & & & & & & \\
22 & - & $S S$ & - & $S S$ & + & $M$ & - & SS & - & SS \\
23 & + & M & - & SS & - & SS & - & SS & + & M \\
26 & + & MS & - & SS & + & M & - & SS & NT & NT \\
\hline
\end{tabular}

\begin{tabular}{|c|c|c|c|c|c|c|c|c|c|c|}
\hline \multicolumn{11}{|c|}{ Família 5} \\
\hline 51 & + & $M$ & - & SS & + & M & - & SS & + & $\mathrm{ML}$ \\
\hline 53 & + & $M$ & - & SS & + & MS & + & $M$ & + & $\mathrm{ML}$ \\
\hline 54 & + & $M$ & - & SS & + & M & + & MS,DF;EF,B & + & $M$ \\
\hline 55 & + & $\mathrm{ML}$ & NT & NT & + & $M$ & + & MS, B & + & $M$ \\
\hline
\end{tabular}

\begin{tabular}{|c|c|c|c|c|c|c|c|c|c|c|}
\hline \multicolumn{11}{|c|}{ Família 6} \\
\hline 61 & + & $\mathrm{M}$ & + & $\mathrm{ML}$ & + & MS & - & SS & + & $M$ \\
\hline 62 & + & $\mathrm{M}$ & + & SS & + & $M$ & + & MS, B & + & $M$ \\
\hline 65 & + & $\mathrm{M}$ & + & $\mathrm{ML}$ & + & $M$ & - & SS & + & $M$ \\
\hline 66 & + & $\mathrm{ML}$ & + & SS & - & SS & - & SS & + & $\mathrm{ML}$ \\
\hline \multicolumn{11}{|c|}{ Família 8} \\
\hline 81 & + & SS & + & $\mathrm{ML}$ & - & SS & + & MS, B & + & $\mathrm{ML}$ \\
\hline 83 & + & $\mathrm{ML}$ & - & SS & - & SS & - & SS & NT & NT \\
\hline 84 & + & $\mathrm{ML}$ & - & SS & + & $\mathrm{ML}$ & + & $\mathrm{ML}$ & + & $\mathrm{ML}$ \\
\hline 85 & + & $\mathrm{ML}$ & + & $\mathrm{ML}$ & + & $\mathrm{ML}$ & + & $\mathrm{MS}, \mathrm{B}, \mathrm{DF}$ & + & $\mathrm{ML}$ \\
\hline
\end{tabular}

- Sintomas: B- bolhosidade; DF- deformação foliar; EF- enrolamento foliar; M- mosaico; ML-Mosaico leve; MS- mosaico severo; NT- não testada; SS- sem sintomas.

** (+) Resultado positivo; (-) resultado negativo.

com comprovada resistência ao WMV2, como Eldorado 300 (Dusi, 1992) e W6 (Tomas e Webb, 1981) e ao vírus do mosaico do zucchini amarelo (ZYMV), relatado em PI 414723 (Gilbert et al., 1994). Esses resultados indicam a possibilidade de serem obtidas linhagens de Tupã com resistência a essas viroses e que a combinação dessas linhagens pode gerar híbridos manifestando resistência múltipla.

As 29 progênies avaliadas para produção e qualidade do fruto apresentaram diferenças significativas $(\mathrm{P}>0,01 \mathrm{e}$ $\mathrm{P}>0,05)$ para todas características, com exceção para a produção (PRODU) (Tabela 2). O efeito das famílias nas progênies, estudado pelo desdobramento dos Quadrados Médios, indicou que para a concentração da colheita (CC), ocorreram diferenças significativas na família 1 e na família 6; para maturação (MATUR) as diferenças foram verificadas na família 6 e 8 ; para o peso médio (PMF), as diferenças significativas foram nas famílias 1, 2 e 3; para o índice de formato (IF), em todas as famílias; para o tamanho da cavidade da semente (DI), nas famílias 1, 5 e 6; para espessura da polpa (EP), nas famílias 1 , 2,5 , e 6 e para a firmeza da polpa nas famílias 1,2 e 8. Para CC, mais da metade dos frutos foram produzidos até os 80 dias. Mas as médias entre as famílias não diferem entre si. A família 1 é muito variável e tem progênie muito precoce (progênie 16) e muito tardia (progênie 15), que aos 70 dias os frutos ainda não havia sido colhidos. A concentração da colheita é uma característica importante em melão, mas ainda pouco avaliada. Cultivos usando linhagens homogêneas mostraram colheitas menos concentradas, com médias de $41,4 \%$ do total dos frutos colhidos aos 70 dias (Paiva et al. 2000a). Quanto à maturação dos frutos, as famílias 5 e 8 mostram progênies com frutos de maturação precoce. Nas progênies $66 \mathrm{e}$ 85 , os frutos atingem a maturação aos 33,8 dias enquanto que a progênie 63 é tardia, com a maturação dos frutos ocorrendo aos 48 dias. Os frutos de melão Amarelo "Eldorado 300" demoram 34,2 dias para atingir a maturação enquanto que os melões do tipo Cantaloupe (Hy Mark) maturam aos 33,1 dias (Paiva et 
Tabela 2. Médias de concentração da colheita (CC); expresso em porcentagem do total de frutos colhidos até aos 70 dias; maturidade (MATUR), em dias entre a polinização até a maturação do fruto e produção de frutos (PRODU), em toneladas por hectare em progênies $\mathrm{S}_{1}$ de melão Tupã. Pacajus, Embrapa Agroindústria Tropical, 2001.

\begin{tabular}{|c|c|c|c|}
\hline Progênies & CC & MATUR & PRODU \\
\hline$\overline{11}$ & $56,90 a^{1}$ & $38,50 a$ & $36,60 a$ \\
\hline 12 & $45,80 a b$ & $40,10 a$ & $26,70 a$ \\
\hline 13 & $75,00 a$ & $39,20 a$ & $32,70 a$ \\
\hline 14 & $55,00 a b$ & $36,80 a$ & $44,40 a$ \\
\hline 15 & $0,00 \mathrm{~b}$ & $42,20 a$ & $24,30 a$ \\
\hline 16 & $100,00 a$ & $37,70 a$ & $21,47 a$ \\
\hline Média família 1 & $55,45 \mathrm{~A}^{2}$ & $34,08 \mathrm{~A}$ & $31,02 \mathrm{~A}$ \\
\hline 21 & $78,30 a$ & $38,60 a$ & $27,40 a$ \\
\hline 22 & $77,50 \mathrm{a}$ & $38,00 a$ & $31,50 a$ \\
\hline 23 & $81,20 a$ & $36,20 a$ & $27,50 a$ \\
\hline 24 & $73,90 a$ & $36,40 a$ & $32,90 a$ \\
\hline 25 & $66,20 a$ & $37,70 a$ & $42,30 a$ \\
\hline 26 & $27,50 a$ & $40,30 a$ & $35,40 a$ \\
\hline Média família 2 & $67,43 \mathrm{~A}$ & $37,86 \mathrm{~A}$ & $32,83 \mathrm{~A}$ \\
\hline 51 & $31,20 a$ & $42,00 a$ & $31,60 a$ \\
\hline 52 & $10,70 a$ & $38,20 a$ & $23,70 a$ \\
\hline 53 & $10,70 a$ & $39,50 a$ & $44,00 \mathrm{a}$ \\
\hline 54 & $47,90 a$ & $38,70 a$ & $40,00 a$ \\
\hline 55 & $40,80 a$ & $36,70 a$ & $51,00 a$ \\
\hline 56 & $11,40 a$ & $39,00 a$ & $35,00 a$ \\
\hline Média família 5 & $25,45 \mathrm{~A}$ & $34,01 \mathrm{~A}$ & $37,55 \mathrm{~A}$ \\
\hline 61 & $16,60 a$ & $41,00 a b$ & $35,80 a$ \\
\hline 62 & $21,80 a$ & $35,00 \mathrm{bc}$ & $36,10 a$ \\
\hline 63 & $35,70 a$ & $42,20 a$ & $30,70 a$ \\
\hline 64 & $77,40 \mathrm{a}$ & $40,20 a b$ & $31,60 a$ \\
\hline 65 & $58,30 a$ & $37,30 a b c$ & $24,00 a$ \\
\hline 66 & $76,70 a$ & $33,80 b c$ & $30,20 a$ \\
\hline Média família 6 & $45,75 \mathrm{~A}$ & $38,25 \mathrm{~A}$ & $31,40 \mathrm{~A}$ \\
\hline$\overline{81}$ & $65,80 a$ & $36,50 a b$ & $22,00 a$ \\
\hline 82 & $48,30 a$ & $40,70 a$ & $34,40 a$ \\
\hline 83 & $88,70 a$ & $34,60 a b$ & $27,40 a$ \\
\hline 84 & $48,80 a$ & $39,30 a b$ & $37,40 a$ \\
\hline 85 & $77,60 \mathrm{a}$ & $33,80 \mathrm{~b}$ & $35,00 a$ \\
\hline Média família 8 & $65,84 \mathrm{~A}$ & $36,98 \mathrm{~A}$ & $31,24 \mathrm{~A}$ \\
\hline Média geral & 51,90 & 38,20 & 32,90 \\
\hline
\end{tabular}

$1 \backslash$ Médias seguida por mesma letra minúscula (na coluna) não diferem entre si $(\mathrm{p}>0,01)$ pelo Teste de Tukey

$2 \backslash$ Médias seguida por mesma letra maiúscula (na linha) não diferem entre si ( $p>0,01)$ pelo Teste de Tukey

a1, 2000a). Dessa forma, a cultivar Tupã pode ser considerada de maturação tardia dos frutos.

Os caracteres de maior importância econômica no melão estão diretamente relacionados ao fruto. As médias na Ta- bela 3 indicam que as famílias 6 e 8 mostram pouca variação no peso dos frutos. Para o índice de formato variam desde redondos (família 1, com $I F=1,02$ ) a levemente oblongos, (família 2, com $\mathrm{IF}=1,21$ ), destacando-se a progênie 55, com frutos com formato oval ( $\mathrm{IF}=1,45)$. Conforme Gurgel (2000), no tipo Amarelo os frutos não devem ultrapassar o peso de 1.800 gramas, que comporta o tamanho exigido pelos mercados dos países europeus e o índice de formato 
Tabela 3. Médias de peso médio do fruto (PMF), índice do formato (IF), diâmetro interno (DI), espessura da polpa (EP) e firmeza da polpa (FP) em frutos de progênies de melão Tupã. Pacajus, Embrapa Agroindústria Tropical, 2001.

\begin{tabular}{|c|c|c|c|c|c|}
\hline Progênies & PM (g) & IF & DI (cm) & $\mathrm{EP}(\mathrm{cm})$ & FP (N) \\
\hline 11 & $1339,00 b^{1}$ & $1,02 a$ & $5,12 c$ & $4,40 a$ & $17,98 a$ \\
\hline 12 & $1279,90 b$ & $1,03 a$ & $5,70 b c$ & $3,81 a$ & $15,57 a$ \\
\hline 13 & $1614,30 a b$ & $1,08 a$ & $6,12 b c$ & $4,45 a$ & $10,98 a$ \\
\hline 14 & $1715,50 a b$ & $0,97 a$ & $6,69 c$ & $3,77 a$ & $7,09 a$ \\
\hline 15 & $1453,00 a b$ & $1,09 a$ & $5,62 a$ & $4,80 a$ & $13,40 a$ \\
\hline 16 & $1901,30 a$ & $0,94 a$ & $7,80 a$ & $3,56 a$ & $10,43 a$ \\
\hline Média família1 & $1550,50 \mathrm{~A}^{2}$ & $1,02 \mathrm{~B}$ & $6,17 \mathrm{~A}$ & $4,13 \mathrm{~B}$ & $12,56 \mathrm{~B}$ \\
\hline 21 & $1239,30 b$ & $1,05 a$ & $5,75 a$ & $3,78 b$ & $22,39 a$ \\
\hline 22 & $1614,20 a b$ & $1,11 a$ & $5,58 a$ & $4,89 a b$ & $10,29 a$ \\
\hline 23 & $1723,70 a b$ & $1,15 a$ & $5,89 a$ & $4,97 a b$ & $7,78 a$ \\
\hline 24 & $1446,70 a b$ & $1,12 a$ & $5,32 a$ & $4,86 a b$ & $16,13 a$ \\
\hline 25 & $1858,80 a b$ & $1,20 a$ & $5,76 a$ & $6,16 a$ & $15,43 a$ \\
\hline 26 & $1281,60 b$ & $1,15 a$ & $5,47 a$ & $4,70 a b$ & $12,82 a$ \\
\hline Média família 2 & $1527,38 \mathrm{AB}$ & $1,13 A B$ & $5,62 \mathrm{AB}$ & $4,83 \mathrm{~A}$ & $14,14 \mathrm{~B}$ \\
\hline 51 & $1286,50 \mathrm{~b}$ & $1,18 b$ & $5,65 b$ & $5,59 a$ & $17,80 a$ \\
\hline 52 & $1233,10 b$ & $1,23 a b$ & $5,09 b$ & $5,03 a$ & $20,63 a$ \\
\hline 53 & $1446,60 a b$ & $1,2 \mathrm{ab}$ & $5,65 b$ & $5,14 a$ & $18,49 a$ \\
\hline 54 & $1305,10 b$ & $1,45 a$ & $5,53 b$ & $4,88 a$ & $17,24 a$ \\
\hline 55 & $1934,40 a$ & $1,01 b$ & $6,75 a$ & $4,26 a$ & $16,13 a$ \\
\hline 56 & $1289,80 b$ & $1,22 a b$ & $5,34 b$ & $5,13 a$ & $14,83 a$ \\
\hline Média família 5 & $1415,91 \mathrm{AB}$ & $1,21 \mathrm{~A}$ & $5,66 \mathrm{AB}$ & $5,00 \mathrm{~A}$ & $17,52 \mathrm{AB}$ \\
\hline$\overline{61}$ & $1539,30 a$ & $1,06 a$ & $5,33 a$ & $4,72 a$ & $19,02 a$ \\
\hline 62 & $1375,20 a$ & $1,06 a$ & $5,26 a$ & $4,49 a$ & $12,79 a$ \\
\hline 63 & $1306,90 a$ & $1,10 a$ & $5,08 a$ & $4,65 a$ & $15,16 a$ \\
\hline 64 & $1102,40 a$ & $1,10 \mathrm{a}$ & $5,37 a$ & $4,10 \mathrm{a}$ & $17,94 a$ \\
\hline 65 & $1207,00 a$ & $1,13 a$ & $5,15 a$ & $4,51 \mathrm{a}$ & $13,77 a$ \\
\hline 66 & $1333,20 a$ & $1,19 a$ & $5,68 a$ & $5,04 a$ & $19,47 a$ \\
\hline Média família 6 & $1310,67 \mathrm{AB}$ & $1,10 \mathrm{AB}$ & $5,31 \mathrm{AB}$ & $4,58 \mathrm{AB}$ & $16,35 \mathrm{AB}$ \\
\hline 81 & $959,50 a$ & $1,06 a$ & $4,84 a$ & $3,91 a$ & $35,6 a$ \\
\hline 82 & $1032,50 \mathrm{a}$ & $1,15 a$ & $4,99 a$ & $4,25 a$ & $27,81 a$ \\
\hline 83 & $1061,00 \mathrm{a}$ & $1,03 a$ & $5,38 a$ & $3,80 \mathrm{a}$ & $21,13 a$ \\
\hline 84 & $1115,00 \mathrm{a}$ & $1,04 a$ & $5,41 a$ & $3,97 \mathrm{a}$ & $17,02 a$ \\
\hline 85 & $1113,50 a$ & $1,11 \mathrm{a}$ & $5,54 a$ & $4,07 a$ & $21,13 a$ \\
\hline Média família 8 & $1056,20 \mathrm{~B}$ & $1,10 A B$ & $5,23 \mathrm{~B}$ & $4,00 \mathrm{~B}$ & $24,53 \mathrm{~A}$ \\
\hline Média geral & 1401,71 & 1,10 & 5,60 & 4,54 & 16,77 \\
\hline
\end{tabular}

$1 \backslash$ Médias seguida por mesma letra minúscula (na coluna) não diferem entre si ( $p>0,01)$ pelo Teste de Tukey

$2 \backslash$ Médias seguida por mesma letra maiúscula (na linha) não diferem entre si ( $p>0,01)$ pelo Teste de Tukey

entre 1,1 e 1,7, característica de frutos oblongos. Esse último parâmetro é importante quando se considera a embalagem, o transporte e a comercialização (Granjeiro et al., 1999). Observa-se que as progênies atendem a exigência no que concerne ao formato e ao peso médio de fruto, com semelhanças ao melão tipo Amarelo.

As características internas do fruto, tamanho da cavidade da semente (DI), espessura da polpa (EP) e firmeza da polpa (FP), conferem o diferencial para aumentar a qualidade e a maior resis- tência ao transporte e armazenamento. A avaliação para estas características mostrou grande variação. Para DI, as diferenças foram observadas entre as médias das famílias: a família 5 apresenta os frutos com o menor DI $(5,23$ $\mathrm{cm}$ ) e a família 3 , frutos com maior EP 
$(5,0 \mathrm{~cm})$. O melão Eldorado 300 produz frutos com a EP de $3,5 \mathrm{~cm}$ e o DI $5,80 \mathrm{~cm}$ (Paiva et al., 2000a). Em outros genótipos de melão Amarelo essa variação foi de $3,1 \mathrm{~cm}$ a $4,8 \mathrm{~cm}$ para a espessura da polpa e de 4,0 $\mathrm{cm}$ a 7,3 cm para DI (Medeiros et al., 2000). Os frutos de 'Tupã' podem ser considerados como tendo EP espessa e DI reduzida. Os resultados mostram que, pelas características internas do fruto ocorrem semelhanças ao melão Amarelo (polpa espessa, ou alto EP) e ao melão Cantaloupe (pequena cavidade, ou baixo DI).

A textura ou firmeza da polpa (FP), apesar de ser um parâmetro físico está relacionada com a solubilização de substâncias pécticas, as quais, segundo Chitarra \& Chitarra (1990), quando em grande quantidade, conferem textura frágil aos frutos. Melões considerados com boa conservação, como os Amarelos, apresentam valores elevados para FP. Essa característica parece sofrer grande influência ambiental, com valores muito variáveis, mesmo no melão Amarelo. No híbrido "Gold Mine" já foram citados valores de 21,22 N (Granjeiro et al. 1999), 32,9 N (Gurgel, 2000) e até de 37,1 N (Sena et al., 2000). Por outro lado, nos melões Cantaloupe a FP se situa ao redor de 23,56 N (Vale, 2000). Especificamente, no híbrido " $\mathrm{Hy}$ Mark" existem citações de 20,35 N (Santos Júnior, 2002), e de 30,17 N a 34,20 N (Almeida, 2002)

As progênies de 'Tupã' mostraram FP variando de $7,78 \mathrm{~N}$ a $35,6 \mathrm{~N}$, com $20 \%$ mostrando valores superiores a $20,0 \mathrm{~N}$, valores próximos aos encontrados nos melões Cantaloupe. Verifica-se portanto, que além da coloração da pol- pa salmão o melão Tupã tem a FP igual ao melão Cantaloupe. A progênie 82 , apresentou FP de 35,1 N, mais próxima dos valores de FP dos melões tipo amarelo. Esta progênie tem a polpa dos frutos de coloração verde.

\section{AGRADECIMENTOS}

Ao CNPq, Programa de Apoio ao Desenvolvimento da Fruticultura Irrigada do Nordeste (PADFIN) e ao Programa Avança Brasil pelo financiamento da Pesquisa.

\section{LITERATURA CITADA}

ALMEIDA, A.S.; FILGUEIRAS, H.A.C.; MENEZES, J.B.; ALVES, R.E.; PEREIRA, M.E.C.; ALMEIDA, A.V. Atividade respiratória e produção de etileno em diferentes híbridos de melão cultivados no pólo agrícola Mossoró-Açú, Horticultura Brasileira, Brasília, v. 19, suplemento CD-ROM, 2001.

CLOUGH, G.H. Coat protein transgenic resistance to watermelon mosaic and zucchini yelows mosaic virus in squash and cantaloupe. Plant Disease, p. 1107-1109, 1995.

CHITARA, A.B.; CHITARA, M.I. Pós-colheita de frutas e hortaliças: fisiologia e manuseio. Lavras: ESAL/FAEPE, 1990. 320 p.

CRUZ, C.D. Programa GENES: Aplicativo Computacional em Genética e Estatística -Viçosa: UFV, 1997. 442 p.

DUSI, A.N. Melão para exportação: aspectos técnicos da produção. Frupex. Brasília. DENACOOP, 1992. 35 p.

GILBERT, R.Z.; KILLE, M.M.; MUNGER, M.; GRAY, S.M. Inheritance of resistance to watermelon mosaic virus in Cucumis melo $\mathrm{L}$. Hortscience, v. 29, p. 107-110, 1994

GRANJEIRO L.C.; PEDROSA, J.F.; BEZERRA NETO, F.; NEGREIROS, M.Z. Qualidade de híbridos de melão amarelo em diferentes densidades de plantio. Horticultura Brasileira, Brasília, v. 17, n. 2 , p. $110-114,1999$

GURGEL, F.L. Adaptabilidade e avaliação qualitativa de híbridos de melão amarelo. 2000. 33 p. (Tese mestrado), ESAM, Mossoró, 2000.
LIMA, J.A.A; VALE, C.C.; MIRANDA, A.C.M.M.; OLIVEIRA, V.B. Identificação sorológica do 'zuchini yellow mosaic virus' em plantios de melão no Rio grande do Norte. Fitopatologia Brasileira, Brasília, v. 21.p. 426, 1996 (Resumo)

McCREIGHT, J.D.; NERSON, H.; GRUMET, R. Melon (Cucumis melo 1.) In: KALLOO G.; BERGH, B.O. Genetic improvement of vegetables crops. Pergamon Press, UK. 1993, 267-294.

MEDEIROS, D.O.; PINHEIRO NETO, L.G.; MARQUES, R.N.; BORGES, R.L.M.; PAIVA, W.O.; Avaliação de caracteres de frutos em progênies de melão amarelo. XV Encontro de Genética do Nordeste

OLIVEIRA, V.B. Caracterização biológica e sorológica de isolados de potyvirus que infectam cucurbitáceas no Nordeste. 2000. 83 p. (Tese mestrado), UFC, Fortaleza, 2000.

PAIVA, W.O.; SABRY NETO, H.; LOPES, A.G.S. Avaliação de linhagens de melão. Horticultura Brasileira, Brasília, v. 18, n. 2, p. 109 -113, 2000a PAIVA, W.O.; BORGES, R.L.M.; GONZAGA NETO, L.G.; MEDEIROS, D.O.; MARQUES, R.N. Seleção de linhagens de melão amarelo com polpa cantaloupe. XV Encontro de Genética do Nordeste. Sociedade Brasileira de Genética. Fortaleza-CE. Resumos. p. 160. 2000b

PAIVA, W.O; BORGES, R.L.M.; PINHEIRO NETO, L.G.; MEDEIROS, D.O.; MARQUES, R.N. Características de melão amarelo com polpa cantaloupe. In: $1^{\circ}$ Congresso Brasileiro de Melhoramento de Plantas, Goiânia-GO. 2001. File// E área $2 \backslash 02$ Resumo 23 htm. 2001.

RUBIES-ANTONELL, C.; BALLANTE, M.; TURINA, M. Viral infections in melon crops of Central Northern Italy. Informatore Fitopatológico, v. 46 v. 7/8, p. 6-10, 1996.

SENA, L.C.N.; GURGEL, F.L.; PEDROSA, J.F.; NEGREIROS, M.Z.; Comportamento de híbridos de melão t.ipo amarelo no município de Mossoró. Horticultura Brasileira, Brasília, v. 18, Suplemento, p. 669-670, 2000.

SHEWFELT, R.L. What is quality. Postharvest Biology and Thecnology, v. 15, p. 197-200. 1999. THOMAS, C.E; WEBB, R.E. W1, W3, W4, W5 and W6 multidisease resistance muskmelon breeding lines. HortScience, v. 16 p. 96. 1981.

VALE, M.F.S. Poda e densidade de plantio em híbridos de melão. 2000. 41 p. (Tese mestrado), ESAM, Mossoró, 2000. 